\title{
ACOSO SEXUAL JUVENIL EN LOS ESPACIOS DE OCIO NOCTURNO: DOBLE VULNERABILIDAD FEMENINA ${ }^{1}$
}

\author{
María Ángeles García CARPintero \\ Universidad de Sevilla \\ CARMEN RUíz REPULLO \\ Universidad Pablo de Olavide \\ NURIA ROMO AvilÉs \\ Universidad de Granada
}

En este artículo se analiza el acoso sexual hacia las chicas jóvenes en los espacios de ocio nocturno.
El objetivo se ha centrado en conocer los posibles riesgos, así como las vivencias y percepciones
en torno a la violencia de género, específicamente el acoso sexual, que tienen lugar en los espacios
de ocio nocturno, analizando a su vez las estrategias y posibilidades de cambio. La metodología
es cualitativa, con 24 entrevistas en profundidad, a personas entre 16 y 22 años. Los resultados
muestran un discurso de espejismo de la igualdad en el ocio nocturno: ellos pueden tener una
sexualidad explícita, ellas deben respetar normas no escritas sobre el uso del espacio público,
horarios y lugares. Ellos normalizan el acoso como un elemento más de la fiesta. Se desarrollan
estrategias grupales diferenciadas tanto de intimidación como de defensa. Las chicas identifican
"puntos negros" o peligrosos. Concluimos que las chicas tienen miedo de ser agredidas
sexualmente, y que los varones utilizan el acoso sexual como ejercicio de poder, perpetuando un
mandato social diferenciado por género en los espacios de ocio nocturnos. PALABRAS CLAVE: ocio nocturno juvenil, violencia, sexting, jóvenes, investigación cualitativa.

Young People and Sexual Harassment in Night-Time Leisure Spaces: Double Female Vulnerability

This article analyses the sexual harassment that girls and young women are exposed to in the spaces of nightlife. The objective is focused on learning the possible risks, as well as the experiences and perceptions concerning gender violence, and specifically sexual harassment, which take place in nightlife spaces, while also analysing strategies and possibilities for change. The methodology used is qualitative, with 24 in-depth interviews with people between the ages

\footnotetext{
${ }^{1}$ El presente estudio forma parte del proyecto "Violencia de Género e Interpersonal en los contextos recreativos de ocio adolescente" (Proyectos de I+D+I del Programa Estatal de Investigación, Desarrollo e Innovación orientada a los Retos de la Sociedad. Plan Estatal de Investigación Científica y Técnica de Innovación. Ministerio de Industria, Economía y Competitividad. Agencia Estatal de Investigación. 2016-2019, FEM2016-77116-C2-1-R. MINECO/FEDER, UE).
}

García Carpintero, María Ángeles, Carmen Ruíz Repullo y Nuria Romo Avilés (2019), "Acoso sexual juvenil en los espacios de ocio nocturno: Doble vulnerabilidad femenina", Lectora, 25: 329348. ISSN: 1136-5781, D.O.I.: 10.1344/Lectora2019.25.20, agcarpin@us.es; nromo@ugr.es; crmenruizrepullo@gmail.com

Recepció: 15 de desembre de 2018 - Acceptació: 29 d'abril de 2019 
of 16 and 22. The results show a discourse of illusory equality in nightlife spaces: boys/young men can have an explicit sexuality, whereas girls/women must respect some unwritten rules on the use of public space, times and places. Boys/men normalize harassment as one more aspect of nightlife. Differentiated group strategies are developed, both of intimidation and defence. Girls/women identify dangers or "black spots". We conclude that girls/women are afraid of being sexually assaulted, and that males use sexual harassment as an exercise of power, perpetuating a gender-differentiated social mandate in spaces of nightlife.

KEY WORDS: recreational night live, violence, sexting, young people, qualitative study.

\section{Introducción, estado de la cuestión y objetivos}

En España recientemente hemos asistido a noticias con extensa exposición mediática, a raíz de casos de violencia sexual contra mujeres jóvenes, muy contestados y denunciados no sólo por las víctimas, sino por toda la ciudadanía. Y en los últimos años está empezando a ser considerada como una forma de violencia de género en los ordenamientos jurídicos de muchos países. Según datos del Informe ONU Mujeres 2018, de los 189 Estados que han firmado la Convención Sobre la Eliminación de Todas las Formas de Discriminación contra la Mujer, 177 no tienen una legislación contra el acoso callejero.

En Europa, el pacto que orienta a los Estados miembros de la Unión Europea (2017) a modificar sus marcos legislativos en materia de prevención y lucha sobre la violencia contra las mujeres es el Convenio de Estambul, firmado en 2011 y ratificado por España en 2014. En dicho convenio se entiende la violencia contra las mujeres y niñas como una violación de los derechos humanos que implica la violencia física, psicológica, económica, la violencia sexual, incluidas las amenazas de realizar dichos actos, en la vida pública o privada (Convenio del Consejo de Europa sobre prevención y lucha contra la violencia contra las mujeres y la violencia doméstica, 2011; Saguy, 2018). Sin embargo, en España no existe una legislación específica sobre el acoso callejero y, a no ser que haya también una agresión física, generalmente estos actos no llegan a denunciarse ni a sancionarse.

El acoso sexual en los espacios de ocio nocturno es una forma de intimidación $\mathrm{y}$ violencia sufrida por las mujeres, fundamentalmente jóvenes y adolescentes, en todo el mundo, producto de una socialización patriarcal, que viola el derecho fundamental de las mujeres a disfrutar del espacio público con libertad y seguridad en el mismo sentido que los varones.

Sin embargo, no existe una definición estandarizada de acoso sexual, específicamente del que ocurre en los entornos de ocio nocturno. El mayor consenso de los autores que han abordado el tema (OCAC, 2015; Zurbano et al., 2016; Rodó de Zárate et al., 2016; SSH, 2018) y el que utilizaremos en nuestro trabajo es el siguiente: el acoso sexual consiste en una diversidad de conductas y prácticas con connotación sexual explícita o implícita, en razón del sexo, género u orientación 
sexual real o percibida, que ocurren de forma unidireccional por una persona extraña a la víctima. Incluye expresiones verbales — silbidos, jadeos, gestos, comentarios sexuales - y conductas intimidantes - acercamientos no deseados, roces, tocamientos, exhibicionismo, persecución-, que consiguen provocar miedo o situación de incomodidad en la persona a la que van dirigidas. Todo ello es fruto de una percepción de dominación simbólica por parte de algunos varones que reafirman con sus actitudes una situación de poder sobre las mujeres que coacciona la libertad de estas, y les da a ellos una sensación de impunidad cuando las acosan sexualmente en los espacios públicos y de ocio nocturno juvenil (Rodó de Zárate et al., 2016; SSH, 2018). Por otra parte, entendemos el ocio nocturno juvenil como salir una noche de fiesta a la calle, a una discoteca o un bar de copas, generalmente en compañía de amistades.

En cuanto a la prevalencia del acoso en jóvenes y adolescentes, diversas investigaciones llevadas a cabo en la última década en países de ámbito occidental como Suecia, EE. UU. o Canadá revelan una incidencia alta de victimización; el 83\% de las estudiantes universitarias estadounidenses según la Asociación Americana de Mujeres Universitarias (AAUW, 2011; Hill y Kearl, 2011) y el 77\% de las chicas suecas encuestadas habían sufrido acoso sexual (Witkowska y Kjellberg, 2005). Además, el $87 \%$ decían que habían padecido secuelas y efectos negativos estresantes tras ser acosadas (AAUW, 2011; Graham et al., 2017). La mayor parte de los incidentes de acoso son verbales - con comentarios sexuales, chistes y gestos-, el $30 \%$ de estas acciones son ciberacoso a través de correo electrónico, Facebook y otros medios electrónicos. Y las chicas son acosadas sexualmente en mayor medida que los chicos, en todas las formas de acoso, tanto a través de los medios virtuales como físicos directos (Hill y Kearl, 2011). También lo sufren algunos varones en la pubertad temprana, fundamentalmente burlas llamándolos gay (Buchanam y McDougall, 2017). Por otro lado, el 50\% de las mujeres europeas declaran haber sufrido algún tipo de acoso desde los 15 años (Katja, 2012; Latcheva, 2017). En cuanto a las consecuencias, tienen efectos negativos en ambos sexos, aunque en mayor porcentaje y severidad en las chicas: insomnio $-22 \%$ ellas, versus $14 \%$ ellos- e impacto emocional y, en el ámbito educativo, aumento del absentismo escolar (AAUW, 2011).

El tipo de acoso más frecuente en la calle es el verbal de contenido sexual explícito para las chicas; y en forma de burlas y hostigamientos por no seguir estereotipos heteronormativos para chicos y chicas. Algunos trabajos señalan que es común llamarlas a ellas lesbianas y a ellos gays (Skoog y Ozdemir, 2016). Esto suele acontecer en la vía pública y en las calles para todas las personas que no cumplan la idea del "deber ser" heteropatriarcal y normativo sobre quién debe ocupar y dominar el espacio público, con lugares y horarios que conforman un espacio urbano 
hostil: calles oscuras, zonas apartadas lejos de la seguridad pública y denominados los "espacios del miedo" (López, 2012).

A este respecto, el miedo se percibe como otro de los condicionantes que experimentan las chicas jóvenes en el uso de los espacios públicos, en concreto de los espacios de ocio nocturno, lo que da un significado diferente a estos espacios en relación a los chicos (Rodó de Zárate et al., 2019). En la investigación realizada con jóvenes en el País Vasco, una de sus principales conclusiones gira en torno a la vivencia de las chicas en los espacios públicos en general, la cual relacionan con el miedo y el peligro, definiendo estos espacios como más hostiles e inseguros para ellas que para los chicos. Así, "el miedo no es solamente una respuesta directa a la violencia que se sufre, sino el resultado de la producción social de la vulnerabilidad de las mujeres" (Rodó de Zárate et al., 2019: 96), ya que no todas las chicas que sienten miedo lo hacen por vivencias propias que han tenido - la mayoría lo tiene por la violencia estructural que supone la dominación masculina en estos escenarios.

El primer artículo que se publica en un medio de comunicación tradicional para denunciar el abuso sexual sufrido por las mujeres en la vía pública corre a cargo de Elizabeth Kusher para la revista Glamour. Este texto tuvo una gran repercusión mediática y supuso una llamada de atención sobre la actitud degradante hacia las mujeres que utilizaban muchos hombres en la vía pública. Actualmente "esta forma discreta y difícil de describir de abuso sexual que han soportado en público durante toda su vida" (Kuster, 1992) se empieza a considerar como una forma de violencia de género hacia las mujeres, que limita su libertad de utilizar el espacio público y es un problema que debe abordarse. En este último año ha habido un incremento importante en el desarrollo de movimientos contra el acoso a nivel mundial. Ejemplo de ello es \#MeToo, una campaña online iniciada en EE. UU. que a día de hoy se ha extendido a más de 180 países (Respers, 2017). En este sentido la Comisión Europea contra el acoso y los abusos sexuales (2017), reconoce el importante papel de la comunidad, las organizaciones juveniles, así como de la sociedad civil - en particular, de los hombres dentro de estas estructurasen los esfuerzos por eliminar todas las formas de violencia contra las mujeres y las niñas, y anima a las víctimas a denunciar a través de los procedimientos formales de las distintas administraciones. Asimismo, pide a los Estados miembros que intensifiquen las medidas de sensibilización en lo que se refiere a los derechos de las víctimas de acoso sexual y discriminación por razones de género. Actualmente hay una preocupación social, recogida por Conferencias Internacionales, Estados, Organizaciones no Gubernamentales y Movimientos Feministas, por reflexionar y tomar medidas sociales, urbanísticas y legislativas. En España se ha visibilizado la problemática del acoso sexual en los espacios de ocio nocturno especialmente desde que ocurriera el caso de "La Manada", esto es, la violación múltiple a una 
chica de 18 años, por parte de cinco hombres en los Sanfermines de 2016. Los agresores grabaron la violación y la compartieron en las redes sociales en un grupo de WhatsApp al que habían denominado "La Manada" (Doria, 2018). Este caso, con aparente impunidad judicial, protagoniza titulares de prensa que no hacen sino reflejar las violencias sexuales que se normalizan y aceptan, culpando y cosificando a las mujeres.

Desde febrero de 2018, el Observatorio contra la Violencia Doméstica y de Género del Consejo General del Poder Judicial (CGPJ) considera como delito machista el acoso sexual para dar cumplimiento al concepto de violencia de género contemplado en el Pacto de Estado, que lo extiende a "cualquier forma de violencia contra la mujer por el mero hecho de serlo", de acuerdo con la definición de Naciones Unidas de violencia de género según la que esta es "todo acto de violencia basado en la pertenencia al sexo femenino que tenga o pueda tener como resultado un daño o sufrimiento físico, sexual o psicológico para la mujer, así como las amenazas de tales actos, la coacción o la privación arbitraria de la libertad, tanto si se producen en la vida pública como en la vida privada" (ONU, 1994). El iv Informe del Observatorio Noctámbul@s, correspondiente a los años 2016 y 2017, que realiza un estudio cualitativo anual sobre la relación entre el consumo de drogas y las violencias sexuales en contextos de ocio nocturno en España, muestra cómo más de la mitad de las chicas encuestadas afirman haber sufrido algún tipo de violencia sexual en los espacios de ocio nocturno, y cómo el consumo, especialmente de alcohol, sigue siendo utilizado por una amplia mayoría de quienes participaron en este estudio como una justificación de la violencia. La utilización, experiencias y percepciones del espacio público en los entornos de ocio juvenil donde se desarrolla esta investigación son diferentes para ellos y ellas, ya que están muy condicionados por el género (Rodó de Zárate et al., 2016). Ellas desarrollan desde la adolescencia una serie de estrategias de protección para evitar los riesgos de estos contextos y lugares. Kathryn Graham, en su estudio sobre jóvenes en entornos de ocio, constata que más del $75 \%$ de las chicas habían sufrido tocamientos y avances persistentes en bares y fiestas (Graham et al., 2017).

Otro de los elementos importantes a analizar en el ocio nocturno juvenil es el uso de la tecnología móvil y las redes sociales como parte importante de la interacción social (TIC). Con el propósito de construir una identidad atractiva y de compartir la fiesta, se suben fotos y vídeos de uno mismo y de los demás a las redes sociales (WhatsApp, Instagram, Facebook y otras). Esto tiene repercusiones individuales y colectivas (Abisheva et al., 2014). Esas imágenes pueden ser utilizadas posteriormente para denigrar la reputación social en el grupo de amigos/as virtuales y se produce un efecto desigual por género que perjudica fundamentalmente a las chicas y las sitúa en una doble vulnerabilidad al difundirse imágenes suyas, consentidas o no, en contextos de ocio nocturno donde a la desinhibición 
generalizada suele sumarse el efecto del alcohol. Estas imágenes sitúan a las chicas fuera del modelo normativo tradicional sobre la feminidad, que sigue exigiéndoles ser buenas, recatadas, decentes, pasivas. Actuar fuera de dicho modelo puede acarrear consecuencias como que sean objeto de insultos, vejaciones y hasta acoso sexual de diversos tipos (Romo Avilés et al., 2019). Esta constatación de las diferencias entre chicos y chicas viene a reafirmar la construcción cultural de la desigualdad en un marco sesgado por las relaciones normativas patriarcales de género en las que la igualdad no es más que un espejismo (Valcárcel, 2008; GarcíaCarpintero, 2018).

Aunque la violencia y el acoso contra las mujeres en los espacios públicos son conocidos y prevalentes, hay pocos estudios científicos, leyes y políticas que den respuesta efectiva al problema del acoso sexual callejero. Es por esto que nos planteamos como objetivo general conocer los posibles riesgos, así como las vivencias y percepciones en torno a la violencia de género, específicamente el acoso sexual, que tiene lugar en los espacios de ocio nocturno, analizando a su vez las estrategias y posibilidades de cambio. Nos planteamos investigar la situación mediante metodología cualitativa, entrevistar a chicas y chicos protagonistas de la acción social y analizar sus discursos.

\section{Metodología}

\section{Muestra}

Se han llevado a cabo 24 entrevistas en profundidad a 10 chicas $(41,66 \%)$ y 14 chi$\cos (58,33 \%)$ adolescentes españoles residentes en dos provincias andaluzas, una de la zona oriental (Granada) y otra de la occidental (Sevilla) de entre 16 y 22 años y que habían consumido alcohol y/o otras drogas en entornos de ocio nocturno. Se establecieron una serie de variables sociodemográficas en la muestra escogida -rural $(12,5 \%)$ o urbano $(87,5 \%)$, género, edad y con pareja $(45,83 \%)$ y sin ella $(54,16 \%)$ - para asegurar la heterogeneidad de perfiles y la visibilización del discurso de los distintos grupos de referencia con objeto de conocer, analizar e interpretar diferentes perspectivas. Se realizaron entrevistas por perfiles hasta la saturación de las categorías. La media de edad fue de 17,7.

\section{Trabajo de Campo}

El trabajo de campo se inició en mayo de 2017. En una primera fase, se llevaron a cabo las entrevistas en profundidad de los y las participantes en distintos centros educativos de Granada y Sevilla - Institutos de Secundaria en Granada y la Facultad de Enfermería, Fisioterapia y Podología de la Universidad de Sevilla. Las entrevistas fueron llevadas a cabo por investigadores e investigadoras miembros del 
equipo con experiencia previa en investigación etnográfica. Las preguntas fueron diseñadas en torno a los bloques temáticos que fueron nuestro objeto de investigación, fundamentalmente las conductas respecto a la violencia de género y sexual en contextos de ocio nocturno; nos preguntábamos asimismo si la utilización de las TIC en estos contextos podría tener alguna relación con este tipo de violencia. Por otra parte, nos resultó de interés explorar la vivencia de los espacios y contextos donde se desarrolla el ocio nocturno. Siguiendo un muestreo intencional, se llevó a cabo un proceso de búsqueda de redes independientes en distintos hábitats — rurales y urbanos. Esto permitió maximizar la captación de diferentes experiencias, así como establecer un mayor control de sesgos en la selección de participantes. El criterio general de inclusión fue el de chicas y chicos de entre 16 y 22 años - estudiantes que vivían con familiares y no eran menores infractores ni estaban en riesgo de exclusión social, que fueran consumidores de alcohol y asistentes a lugares de ocio juvenil. La selección de los perfiles más ilustrativos de chicas y chicos que fueron entrevistados/as se realizó a partir del proceso de contactación. Las entrevistas individuales permitieron explorar en profundidad tanto aspectos personales e interpersonales como aspectos del contexto socio-cultural.

\section{Análisis de los datos}

Todas las entrevistas fueron grabadas y transcritas de forma literal. La duración media de las entrevistas fue de 60 minutos. La finalización del proceso de recolección de datos se determinó siguiendo el principio de saturación teórica. Se llevó a cabo un análisis de contenido sumativo. Tras la primera lectura general de las trascripciones, en la que participaron varios miembros del equipo, se realizó una primera identificación de códigos y categorías. Esta primera confrontación de categorías sirvió para consensuar criterios sobre el proceso de codificación y unidades temáticas de interés. Con posterioridad, otro miembro del equipo de investigación cotejó las categorías identificadas. Este proceso de triangulación permitió testar el nivel de consistencia y resolver discrepancias. Tras la codificación, se extrajeron las unidades de análisis más significativas y se identificaron las interrelaciones entre los distintos temas. Todo este proceso analítico se desarrolló con el apoyo del programa QSR NVivo 11.

\section{Consideraciones éticas}

El estudio fue aprobado por la Comisión de Ética en Investigación de la Universidad de Granada (CEI-UGR / 883). Todas las personas menores de edad participantes en el proyecto accedieron de forma voluntaria a ser entrevistadas, recibiendo información sobre el estudio, así como una carta de compromiso de confidencialidad firmada por el equipo de investigación. Las familias también firmaron un consentimiento informado de conformidad con dicha participación. 


\section{Fundamentación epistemológica}

Desde el punto de vista metodológico, este proyecto fue definido desde una perspectiva feminista. Para entender en toda su dimensión el acoso sexual a chicas en espacios de ocio nocturno se hacía necesario adoptar una perspectiva relacional del género, asumiéndolo como una construcción social creada y redefinida a través de la interacción cotidiana con los otros (West y Zimmerman, 2009). Esto llevó a la inclusión de chicos en el estudio. Los resultados que se presentan deben tomarse como una muestra ilustrativa de un conjunto de discursos que circulan en el contexto de estudio en el momento actual. Del mismo modo, el equipo de investigación asumió desde el inicio que, por el hecho de adoptar una perspectiva interpretativa construccionista de la realidad social, estaba produciendo activamente datos cualitativos de forma conjunta a las personas participantes en el estudio. Ello se consideró un elemento clave dentro del proceso de investigación, dada la importancia otorgada desde la investigación feminista a la interacción directa con quienes participan en la investigación, así como a la reflexividad y procesos subjetivos en la construcción del conocimiento (Rose, 2001).

\section{Las conductas}

\section{El acoso sexual como parte de la fiesta: ¿Ellos “campeones” y Ellas “facilonas”?}

Lo primero que llama la atención en los discursos de chicas y chicos que han participado en la investigación es su coincidencia acerca de que no viven de la misma forma el ocio nocturno. Hay una doble moral y un doble rasero para valorar de distinta forma las conductas en chicos o en chicas.

Ellos, como vemos a través de sus discursos, afirman que el acoso sexual es parte del ocio, como si se tratara de un ingrediente más de la fiesta. Salen a la calle con la intención de ligar y tener algún contacto sexual - para ello las tácticas van desde insinuaciones y comentarios procaces, silbidos, propuestas explicitas de mantener sexo en el baño o salir del local, a otras más intrusivas con acercamiento, acorralamiento, tocamiento, o persecución. Normalizan el acoso sexual, aunque son conscientes de que están ejerciendo poder y que son situaciones de violencia contra las chicas a las que acosan. También llama la atención que, aunque lo perciben como algo que "hacen los otros", no intervengan para frenarlo. En este sentido, podríamos observar una cierta complicidad con quien realiza el acoso - por una parte lo ven como una forma de violencia, sin embargo, no hacen nada para evitarlo ni se implican en este tipo de situaciones de acoso.

Pero lógicamente los niños es lo que te he dicho, se ponen a tocar culos. [...] Que una niña haga eso o te entre a ti es más difícil... una niña sale 
de fiesta y va a haber diez niños detrás, y si un niño sale de fiesta pues no va a pasar nada de eso. (Luis, 18 años)

Acosarla. Ir detrás de ella pidiéndole el número, toqueteándola, diciéndole vámonos a los baños, diciéndole vámonos fuera... cosas de esas. [...] Pues acoso verbal hay, por ejemplo, diciéndoles "Vente conmigo, que te voy a hacer pasar un buen rato" o cosas así y "Vámonos a los baños" y ya pues lo de tocar, ya empiezas a manosear a la chica o el culo. (Hugo, 20 años)

Pues sí, claro, pero es que violencia yo ya lo vería en el sentido de que... cuando ya te pones a decirle o a vocear o a vociferar a una niña por el cuerpo que tiene, para mí eso ya es violencia. (Gabriel, 22 años)

Para los varones hay una lógica de masculinidad que se relaciona directamente con la idea de sexualidad expeditiva (Rodríguez Santero et al., 2017). Un hombre promiscuo suele ser considerado entre sus iguales chicos como un "campeón", mientras que a ellas las situará en la posición de chica frívola. Además, también se percibe entre los discursos masculinos, cierta distinción entre las chicas que creen que van a estar "abiertas" a los deseos sexuales de ellos y las que no.

Para follarte a una niña en una noche, tiene que ser la niña muy abierta en ese sentido. Lo máximo es que te haga una mamada o poco más. Hacerle tú un dedo. (José, 16 años)

Ellas viven los espacios de ocio nocturno como una situación de "riesgo previsto", ya que saben de antemano que pueden sufrir algún tipo de acoso, de distinta índole e intensidad. Las chicas lo tienen normalizado, y tienen que asumirlo si quieren disfrutar de la fiesta y del espacio público. El desenlace dependerá de distintos factores individuales, colectivos y del entorno. Dependerá también de cómo algunos chicos se tomen la negativa o actitud de la chica ante su acoso, es decir, la manera cómo responden ellas ante la insistencia de ellos.

Empezó uno, me dijo “Tú tienes cara de chuparla ¿Me la chupas?”. Pero vamos a ver $¿ E s$ que no puedo ir tranquila por la calle sin que tú me tengas que decir cosas? Pues ese momento aparte de incómodo, que tú no te encuentras bien porque te asustas... porque que te venga un grupo de niños detrás de ti a decirte cosas, te asustas y yo lo pasé muy mal. [...] Y nos encontramos un grupo de niños que empezaron a silbar, a mi silbar me da igual, luego empezaron a ir detrás de mí y empezaron a tocarme el culo y yo "Pero vamos a ver ¿Pero es que yo no puedo estar tranquila andando 
por la calle?". Encima de todo que me están molestando, me tienen que estar tocando el culo, me tienen que estar diciéndome... que qué me dijeron de cosas... (Ana, 17 años)

Ellas están en la encrucijada entre ser tachadas de "estrechas", o colocarse en el extremo contrario, la posición de "facilona", en el caso de que accedan al juego. Para evitar esto, no pueden dar rienda suelta a sus deseos en las mismas condiciones que los varones. No deben transgredir la "norma de género" de no ser o mostrarse decentes. Transgredir la norma las sitúa, tanto para ellos como para las otras chicas, en una posición de riesgo que guarda especial relación con su forma de estar, vestir y ser.

Sí, porque si ya ves que lleva un escote más grande o unos pantalones muy cortos, ya te crees que es una guarrilla y entonces tienes que ir "Ésta va a caer, ésta es vaya..." [...] Eso es lo que piensan los chicos, las chicas también, cuando a lo mejor sin querer juzgas a una persona por cómo va vestida y dices "Ésta es una guarrilla, ésta va a lo que va" [...]. Después me quejo si me lo hacen a mí, pero yo la verdad es que sin querer a veces juzgo. (Lola, 16 años)

Pues a lo mejor una niña se pone a bailar en plan como a ella le gusta, y a lo mejor un niño coge y dice "mira esa" no sé qué... Como que si una niña baila de un estilo u otro es porque es más facilona para entrarle, ¿me entiendes? [...] En plan que si a lo mejor baila, yo qué sé, moviendo el culo pues dicen que esa va a ser facilona y le entran. [...] Por ejemplo, una vez a un amigo mío le gustaba una niña, y la niña pues se veía que era bastante sueltecilla y eso. Así que mi amigo empezó a arrimarse así a ella y pues... eso. [...] Hombre, las niñas si se ponen un vestido más corto o un pantalón más corto o algo es lo que te he dicho antes, que si la ve un niño va a decir "pues esta es más facilona". (Luis, 18 años)

\section{La insistencia y la negativa. Cuando "no es no" se queda corto}

Hay coincidencias discursivas entre chicas y chicos en que el acoso sexual se mantiene a pesar de que la chica se niegue o proteste, la insistencia por parte de ellos es clave, y aparece en los discursos de manera reiterativa. Entronca con la idea patriarcal de que el varón tiene que acechar, y perseguir su objetivo hasta que lo consiga, como parte de la erótica del poder. Se espera que mientras ellos "insisten", ellas "controlen". Una cuerda tirante que guarda especial relación con lo que se espera de unas y otros en materia sexual: ellas tienen que "respetarse" pero también agradarlos, ellos tienen que insistir y "ser satisfechos". Ahora bien, si una chica no 
desea tener relaciones afectivas y sexuales con un chico, ¿por qué su negativa no frena el intento de este? Pareciera que el "no" de ellas no modifica la expresión del deseo de ellos, que, en algunos casos, siguen creyendo tener derecho a "ser satisfechos":

A lo mejor que un chico vaya con intenciones de ligársela a la chica y tal y ella que no quiere, y el chico sigue y sigue. (Sebastián, 18 años)

Las chicas experimentan sentimientos negativos de falta de respeto, enfado o sensación de violencia, ante las conductas relacionadas con el acoso físico y los tocamientos sexuales. Utilizan distintas estrategias de protección y disuasión múltiple, que van desde las expresiones faciales de desagrado, la negativa directa verbal, hasta pedir ayuda de amigos. Otras veces las respuestas de defensa son mediante agresión, evasión o el abandono del establecimiento. La experiencia y el ejercicio de la negativa son distintas para los varones y las mujeres: la percepción que tienen ellas es que el "no es no" no se respeta y que la última voluntad corresponde, en la mayoría de las ocasiones, al chico.

Ella puede decir que no, ahora que el otro lo acepte es otra cosa. (Patricia, 17 años)

Yo tengo amigas que tienen mucho carácter y es verdad que si dicen no es que no, y es más, ellas tienen mucha fuerza y todo, pero luego hay otras que están más débiles. (Ana, 17 años)

Pareciera con ello que no basta solo decir que "no", sino que las chicas deben continuar con estas premisas toda la noche, de lo contrario, la única salida que les quedaría sería la huida de estos espacios de fiesta. El acoso sexual en los espacios de ocio nocturno se percibe como algo "normalizado" por parte de las chicas y de los chicos. Sin embargo, son ellas quienes tienen que buscar estrategias para afrontarlo, denunciarlo o frenarlo.

Le dije que se apartase de mí, que se fuese. [...] Entonces yo me sentí muy incómoda en ese momento, si te estoy diciendo que no, jes que no! (Lola, 16 años)

Si te insisten les pegas una hostia y se van. Otros no, otros te insisten, pero cuando ya están bebidos, no hay forma de que se vayan. [...] Te cogen para intentar llevarte a algún lado y yo "Que me dejéis en paz", yo en cuanto me cogen me lío a patadas, pero es que hay otras niñas que les cogen y es que ni siquiera se defienden y ya está y si lo quieren hacer por 
no tener peleas, pues lo hacen, pero yo no. A mí que no me toquen, es que si yo no quiero, ¡yo no quiero! (Patricia, 17 años)

\section{El alcohol como desinhibidor}

Otra de las coincidencias que encontramos en sus discursos tiene que ver con las situaciones de acoso a mujeres bajo la influencia del alcohol. El alcohol se utiliza fundamentalmente como agente desinhibidor para iniciar el acercamiento y acoso sexual: ellos suelen utilizar técnicas como invitarlas a copas para ligar o aprovechar situaciones en que las chicas están bebidas para ir más allá. Sin embargo, la percepción de la utilización del alcohol como deshinhibidor tiene un sesgo de género; mientras que generalmente el grupo no lo desaprueba en ellos, en ellas es censurado tanto por otras chicas como fundamentalmente por chicos. Son etiquetadas como "guarras" puesto que el alcohol baja el nivel de alerta y hace que parezcan estar más accesibles. Bajo esta lógica machista dentro del ocio nocturno juvenil, los chicos aprovechan la euforia y el alcohol para colocar a las chicas en coyunturas de vulnerabilidad.

Encontramos nuevamente que ante un acoso sexual se sigue culpabilizando a la víctima y desculpabilizando al agresor. En muchos casos los chicos no respetan la circunstancia de vulnerabilidad de la chica y no recaban su consentimiento para tener contacto sexual, llegando a situaciones que ellos mismos catalogan como violación. Sin embargo, lo más llamativo de nuevo se sitúa en la posición de aquellos chicos que, aunque rechazan y son conscientes de la violencia sexual que ejercen "los otros", no hacen nada para frenarla.

La chica estaba sola, y nosotros miramos a la chavala y la chavala estaba con un ojo mirando para Cuenca y el otro en órbita, y a mí me dio mucha pena porque en ese momento le dijimos "tío, déjala, porque te puedes meter en un marronazo que flipas, y aparte lo que estás haciendo es violación", pero él dijo que pasaba y se quedaba, pero me imagino que lo hicieron. (Iván, 16 años)

\section{El grupo. El mimetismo, estrategias de acoso y defensa}

Las estrategias grupales, el número y sexo de los componentes, al igual que los movimientos que se producen dentro de él, son de gran importancia. Para ellos, el grupo reafirma y refuerza los comportamientos de depredadores dentro de una manada, que puede entenderse como un grupo de chicos que comparten el mismo código de actuación, creen tener derecho a ser satisfechos sexualmente cuando ellos lo deseen, y, para ello, utilizan estrategias de diversa índole que van desde el 
piropo, el chantaje, el acoso e incluso la agresión. La calle, y en concreto el ocio nocturno, se percibe como un lugar de posibilidad para la manada y de riesgo para la presa, que deberá, en base a estas lógicas de poder, tener cuidado para no ser cazada. Adoptar este rol determinado es ejercer una relación de poder naturalizada por la socialización diferencial de género (Megías Quirós et al., 2005). En esos momentos, se producen mimetismos con estrategias de acoso, como ir rodeando a la víctima en semicírculo.

A lo mejor si se encuentran a una chica sola, van cuatro, no va uno solo, van cuatro a hacerle el semicírculo. Le hacen el semicírculo, la acorralan y le dicen "Vente con nosotros, tal, te invitamos a algo, tenemos no sé qué". [...] He visto a chicas que a lo mejor han ido solas, no han ido con nadie y la empiezan a acorralar. (Lorena, 16 años)

Para ellas, el grupo funciona como agente protector, que ofrece seguridad ante situaciones comprometidas o de cierto peligro. En su caso, suelen ser grupos de amigas o mixtos, que ofrecen más seguridad. Además, tienden a una actitud intervencionista y ayudan a otras chicas que están siendo acosadas. Pero, incluso dentro de los grupos mixtos, las estrategias de protección, defensa y denuncia las protagonizan generalmente las chicas; los chicos solo intervienen cuando son interpelados por sus amigas.

Si tú vas con niños a lo mejor no te dicen nada, que vas con sólo niñas, sí que te van diciendo cosas. (Lola, 16 años)

Si veo a una chiquilla así tan pequeña y él está metiendo ahí que la veo que le está presionando de una manera que no es ni normal, pues ya alguna vez hemos cogido una amiga y yo y hemos sacado a la chica mientras otros apartaban al chico. (Patricia, 17 años)

Se utilizan mimetismos y maniobras corporales de defensa, como agruparse muy juntas, "apiñarse”, o situarse en los lugares públicos con la espalda protegida. En definitiva, se trata de buscar estrategias de protección ante los riesgos, códigos de conducta que ellas van configurando en la medida en que van sufriendo o conociendo situaciones concretas de acoso sexual.

Solemos estar en la barra las chicas, en plan que las chicas están de espalda a la barra para que no sucedan ese tipo de cosas porque no es agradable que te pase alguien por detrás y te agarre del culo, no es agradable... Entonces pues solemos hacer esto de estar con el culo pegado a donde sea y los chicos delante, porque tampoco es plan. (Andrea, 18 años) 


\section{El papel de las TIC en los espacios de ocio}

Los resultados arrojados por nuestro trabajo demuestran que la difusión de imágenes de chicas en contextos de fiesta y ocio nocturno a través de las redes, casi siempre sin consentimiento expreso, aumenta la sensación de vulnerabilidad en las chicas. Ellas, a nivel individual, no solo tienen que ser virtuosas sino también parecerlo. Solamente así podrán velar por su propia integridad dentro de un marco sesgado por las relaciones tradicionales de género y el machismo. Del mismo modo que deben ser prudentes en la forma de estar en el espacio público y estar alerta en todo momento, también deben controlar sus fotos, poses y vídeos, porque se les responsabiliza por la imagen que proyectan hasta el punto que se desaprueba tanto por los varones como también por el resto del grupo, incluidas otras chicas, y ellas mismas acaban por autoinculparse. Que las chicas difundan imágenes suyas en la calle tiene repercusiones concretas sobre su experiencia en el espacio público, ya que su cuerpo es sexualizado por la mirada masculina (Rodó de Zárate et al., 2016).

Pues a no ser que me hagan fotos así... pilladones, como una foto en la que estaba yo en el baño, lo típico de que estamos varias en el baño y estaba yo... lo típico, sentada en el váter y van y me hacen una foto y la suben y yo “¿Pero qué hacéis con vuestra vida? ¿Por qué tenéis que subir eso?” (Patricia, 17 años)

¿Pero qué necesidad tengo yo de que me vea, por ejemplo, todo Instagram o todo Facebook borracho? (Ana, 17 años)

En otros casos se difunden fotos de grupo y selfies que pueden tener más carga erótica o sexualizada, incluso sexting, al producirse en momentos de fiesta y desinhibición en los entornos de ocio.

\section{Los espacios}

\section{El ocio nocturno y el miedo}

Ellas tienen miedo, no se sienten seguras en el espacio público. Tienen detectados puntos negros dentro del ocio nocturno, fundamentalmente las calles y zonas de acceso a los bares y discotecas, donde, según las horas, aumenta el peligro y el riesgo de ser agredidas sexualmente. Esta situación de amenaza continua hace sentir a la mujer insegura e intrusa en el espacio público de ocio nocturno. Se evidencia que el acoso y la amenaza de violencia sexual por parte de los varones se utiliza como arma de dominación simbólica territorial: ciertos espacios públicos, como los espacios lúdicos y festivos, los más deseados por los y las jóvenes, no son 
seguros para las mujeres a ciertas horas. Son los chicos los que los dominan en grupo y pueden decidir quién puede y quién no puede transitarlos de forma segura.

Al salir de fiesta o ya de volver de fiesta o al irte ¿No?... A veces, pero no es en la discoteca, es al irte a tu casa, que hay cuatro matados por ahí diciendo cosas, pues sí [...] Un día fuimos a hacer pipí y vino un niño detrás que conocíamos de vista, y empezó a decir que hiciésemos un trío, no sé qué, te toqueteo por aquí, por allá, y claro, pues yo ya me puse fatal... (Lola, 16 años)

En los espacios privados lúdicos, bares, discotecas y zonas de marcha, tienen como protección a las personas que trabajan en el lugar, camareros y personal de seguridad. Esa protección desaparece cuando salen a la calle e incluso en zonas del local más desprotegidas de vigilancia como los baños.

He visto a chicas que a lo mejor han ido solas [al baño], no han ido con nadie y la empiezan a acorralar y tienes que empujarlos y decir "Oye, te estás pasando, para ya” y decirle al camarero “¿Podrías por favor quitármelos de encima?" y tiene que ir el camarero y decirles "Por favor, sálganse de aquí" [...] Y son momentos desagradables porque a lo mejor una se quiere ir al baño o lo que sea y van detrás [...] Ha habido amigas mías que han ido solas [al baño], porque no podían aguantar más y sí les ha pasado y hemos tenido que ir el grupo entero a por ella. (Lorena, 16 años)

Los discursos de las chicas que han participado en la investigación muestran cómo salir del espacio de protección del grupo de sus amistades, o ir solas por la calle cuando salen de los establecimientos de fiesta, aumenta el riesgo de ser agredidas y, por tanto, el miedo. Así, en la experiencia que tienen de la calle y otros espacios se construye también una identidad de género desigual: son lugares de inseguridad que condicionan restricciones a la libertad de las mujeres y transmiten un mensaje de dominación masculina para que se sepa a quien pertenece el lugar, la calle y la noche, elementos implícitos en el ocio nocturno. Detectamos acoso y violencia sexual en los espacios de ocio nocturno, ejercida por los chicos hacia las chicas. Este acoso sexual se utiliza por parte de los varones como una estrategia de dominio social (Morganson y Major, 2012).

\section{Discusión y conclusiones}

De las entrevistas realizadas a chicas y chicos podemos confirmar que ellas sufren una doble vulnerabilidad en razón del género, en cuanto a seguridad física y a la imagen social que de ellas se proyecta. 


\section{La seguridad, el grupo y los espacios peligrosos}

En el ocio nocturno se perpetúa un discurso de espejismo de la igualdad (Valcárcel, 2008). Ellas consideran que son iguales a los chicos y que pueden realizar las mismas acciones y disfrutar del espacio público del ocio, o transitar por las calles a altas horas de la noche con el mismo grado de seguridad o inseguridad que exista para los chicos. Sin embargo, no es así, ya que ellas deben añadir otro factor de riesgo: ser mujeres.

Las chicas tienen miedo a ser agredidas sexualmente en los espacios de ocio nocturno. En este sentido, lo que queda claro a través de los discursos tanto de unas como de otros, es que las lógicas del poder patriarcal siguen muy presentes. Se reafirma en esta investigación la idea de que el ocio nocturno es heteronormativo y patriarcal, y no es seguro para las chicas. Así en la experiencia que tienen de la calle se construye también una identidad de género desigual. Encontramos un comportamiento del "deber ser" y del mandato social diferenciado por género, fruto de una socialización diferencial de género desde la infancia, que predice que las mujeres rechazarían una relación sexual inmediata, mientras que los hombres tienden a valorar más el amor lúdico, el sexo casual y la obtención del máximo número de parejas posibles (Rodríguez Santero et al., 2017).

Las estrategias de insistencia y acoso utilizadas por los varones, unidas al consumo de alcohol como elemento desinhibidor están normalizadas dentro de una visión machista de que la calle, cuanto más avanza la noche y dependiendo de las zonas, pertenece a los hombres. La mujer que se expone a transitarla puede ser objeto de acoso en distintos grados — desde burlas, silbidos o palabras soeces a otras actitudes más intrusivas (Romo Avilés et al., 2017).

A nivel colectivo el grupo también tiene distinto comportamiento de género. Para ellos, ir en grupo es un elemento de superioridad que los reafirma en sus conductas de acoso. Para ellas, ir en grupo es un factor positivo que las acompaña y en muchos momentos surte efecto protector mediante la activación de distintas estrategias de defensa.

En cuanto al entorno, la percepción por parte de las chicas que han participado en la investigación es que tienen detectados puntos negros de inseguridad, lo que podrían denominar el “mapa del miedo" (López, 2012; Rodó de Zárate et al., 2019). Las calles periféricas a los lugares que concentran el ocio nocturno juvenil, fundamentalmente las zonas de acceso a los mismos y los baños de los locales, por ser sitios más solitarios o con menos vigilancia. Los lugares privados de ocio, tanto bares como discotecas, resultan ser sitios más seguros que los espacios públicos, ya que el personal que trabaja en los mismos, camareros o vigilantes de seguridad, son agentes protectores ante situaciones violentas o desagradables. 


\section{Sesgo de género en la imagen social proyectada}

El uso de los dispositivos móviles y las TIC en los contextos recreativos, con la difusión, consentida o no, de imágenes supone un elemento más que acrecenta la sensación de vulnerabilidad para ellas, puesto que se pueden utilizar para quebrantar el respecto a su privacidad, y distorsionar la imagen social que proyectan dentro de los grupos y redes sociales. Este uso de las TIC, que tiene también un sesgo de género, afecta de distinta forma a chicos que a chicas. Para ellos ser grabados en estado ebrio o poses promiscuas no afecta a su reputación, en todo caso, suelen considerarlo divertido y un indicador de su papel protagonista en la fiesta; para las chicas, si esto ocurre, la imagen que proyectarían dentro del grupo en las mismas circunstancias sería negativa y peyorativa (Megías Quirós et al., 2005; Rodríguez Santero et al., 2017; Romo Avilés et al., 2019).

Por tanto, observamos que los códigos del ocio nocturno tienen un claro componente patriarcal - los espacios de ocio nocturno están diseñados desde parámetros de poder masculino que suponen una limitación de libertad, movimiento y disfrute del espacio público para las mujeres y que, si no se revierten con medidas protectoras sensibles al género, perpetuarán la violencia contra las mujeres en estas generaciones de chicas jóvenes y adolescentes que se socializan en el miedo. Se trataría pues de abordar la prevención de esta violencia sexual socializando a los chicos en una educación afectiva y sexual cuya primera premisa sea contar con el consentimiento de las chicas para cualquier tipo de relación. En este sentido, habría que educar a los chicos a aceptar que ellas no tienen por qué estar en continua alerta por ser acosadas; son ellos, por el contrario, quienes deben aprender a no acosar. Seguir educando a las chicas a tomar medidas de cuidado y protección no cambia las asimetrías de poder de los espacios de ocio nocturno. Y es una cuestión importante a tener en cuenta en términos de prevención.

Se necesita un cambio cultural para reducir los impactos negativos sustanciales del acoso sexual a las mujeres en los espacios públicos en general y particularmente en entornos de ocio nocturno. Se deberían implementar iniciativas sensibles al género que minimicen los espacios de riesgo que facilitan situaciones de acoso y agresiones, mediante una planificación urbanística y medidas de seguridad que minimizaran los puntos peligrosos. En definitiva, enfatizamos la necesidad de una educación no sexista y de diseñar estrategias institucionales que fomenten el disfrute de chicas y chicos en libertad.

\section{REFERENCIAS BIBLIOGRÁFICAS}

Abisheva, Adiya, Venkata Kiran-Garimella, David García e Ingmar Weber (2014), "Who Watches (And Shares) What on YouTube? And When?: Using Twitter 
to Understand YouTube Viewership", Proceedings of the 7th ACM International Conference on Web Search and Data Mining: 593-602. $<$ https://ingmarweber.de/wp-content/uploads/2014/02/Who-Watches-and-S hares-What-on-YouTube-And-When-Using-Twitter-to-Understand-YouTu be-Viewership.pdf>

Consejo de Europa (2011), Convenio del Consejo de Europa sobre prevención y lucha contra la violencia contra las mujeres y la violencia doméstica, European Treaty Series (ETS). <https://rm.coe.int/1680462543>

Doria, Javier Lorente (2018), "El Tribunal Superior de Navarra confirma la condena de La Manada a nueve años de cárcel por abuso sexual”, El País, 5 de diciembre. <https://elpais.com/sociedad/2018/12/05/actualidad/1543995494_ 456176.html>

García-Carpintero, María Ángeles (2018), "La construcción cultural de las desigualdades y la violencia basadas en el género y sus repercusiones en la salud", Género y salud. Apuntes para comprender la desigualdad, Rosa Casado y María Ángeles García-Carpintero (coords.), Madrid, Editorial Díaz de Santos: 23-39.

Graham, Kathryn, Sharon Bernards, Antonia Abbey, Tara M. Dumas y Samantha Wells (2017), "When Women Do Not Want It: Young Female Bargoers Experiences with and Responses to Sexual Harassment in Social Drinking Contexts", Violence Against Women, 23 (12): 1419-1441.

Hill, Catherine y Holly Kearl (2011), Crossing the Line: Sexual Harassment at School, Nueva York, AAUV.

Kuster, Elizabeth (1992), “Don't 'Hey, Baby’ Me: How to Fight Street Harassment”, Glamour: 308-334. <https://www.coroflot.com/ElizabethKuster/GlamourMagazine-Cover-Story-Street-Harassment>

Latcheva, Rossalina (2017), "Sexual Harassment in the European Union: A Pervasive but Still Hidden Form of Gender-Based Violence", Journal of Interpersonal Violence, 32 (12): 1821-1852.

López, María Añover (2012), "Los espacios del miedo, ciudad y género. Experiencias y percepciones en Zaragoza”, Geographicalia, 61: 25-45.

Megías Quirós, Ignacio, Elena Rodríguez San Julián, Susana Méndez Gago y Joan Pallarés Gómez (2005), Jóvenes y Sexo. El estereotipo que obliga, el rito que identifica, Madrid, FAD.

Morganson, Valerie J. y Debra A. Major (2014), "Exploring Retaliation as a Coping Strategy in Response to Customer Sexual Harassment”, Sex Roles, 71: 83-94.

Observtorio Noctámbul@s (2018), Espacio público, violencias sexuales y ocio nocturno. $4^{\circ}$ Informe anual 2016-17, Ana Burgos garcía (coord.), Barcelona, Fundación Salud y Comunidad. 
Observatorio Contra el Acoso Callejero (OCAC) (2015), ¿Está Chile dispuesto a sancionar el acoso callejero? Estudio de caracterización y opinión sobre el acoso sexual callejero y sus posibles sanciones, marzo <https://www.ocac.cl/wpcontent/uploads/2015/03/Informe-Encuesta-OCAC-2015.pdf>

Organización de las Naciones Unidas (ONU) (1994), "Declaración sobre la eliminación de la violencia contra la mujer”, Asamblea General. <http://www. un.org/es/comun/docs/?symbol=A/RES/48/104>

ONU Mujeres (2018), "Acabar con la violencia contra las mujeres y niñas". $<$ http://www.unwomen.org/es/search-results?keywords=\%E2\%80\%9CAcabar \%20con\%20la\%20violencia\%20contra\%20las\%20mujeres\%20y\%20ni\%C3\%B 1 as $\% \mathrm{E} 2 \% 80 \% 9 \mathrm{D}>$

Respers France, Lisa (2017), “\#MeToo: Social Media Flooded with Personal Stories of Assault", CNN, 16 de octubre <http:/www.cnn.com/2017/10/15/entertainm ent/me-too-twitter-alyssa-milano/index.html>

Rodó de Zárate, Maria, y Jordi Estivill i Castany (2016), ¿La calle es mía? Poder, miedo y estrategias de empoderamiento de mujeres jóvenes en un espacio público hostil, Vitoria, Instituto Vasco de la Mujer.

Rodó de Zárate, Maria, Jordi Estivill i Castany y Nerea Eizagirre (2019), "Configuration and Consequences of Fear in Public Space from a Gender Perspective”, Revista española de investigaciones sociológicas, 167: 89-106.

Rodríguez Santero, Javier; María Ángeles García-Carpintero y Ana María Porcel Gálvez (2017), "Los estilos de amor en estudiantes universitarios. Diferencias en función del sexo-género", Revista internacional de sociología, 75 (3): 1-13.

Romo Avilés, Nuria, María Ángeles García Carpintero y Laura Pavón Benítez (2019), "Not without My Mobile Phone: Alcohol Binge Drinking, Gender Violence and Technology in the Spanish Culture of Intoxication”, Drugs: Education, Prevention and Policy, 1-11.

Rose, Gillian (2001), Visual Methodologies: An Introduction to the Interpretation of Visual Materials, Londres, SAGE Publications.

Saguy, Abigail C. (2018), "Europeanization or National Specificity? Legal Approaches to Sexual Harassment in France, 2002-2012", Law \& Society Review, 52: 140-171.

Stop Street Harassment (SSH), (2018), "2018 Study on Sexual Harassment and Assault", 21 de febrero. <http://www.stopstreetharassment.org/>

Skoog, Therése y Sevgi Ozdemir (2016), "Physical Appearance and Sexual Activity Mediate the Link Between Early Puberty and Sexual Harassment Victimization in Male Adolescents", Sex Roles, 75: 339-348. 
Unión Europea (2017), "Resolución del Parlamento Europeo, de 26 de octubre de 2017, sobre la lucha contra el acoso y los abusos sexuales en la Unión Europea (2017/2897[RSP])". <https://eur-lex.europa.eu/legal-content/ES/TXT/?uri=C ELEX:52017IP0417>

Zurbano Berenguer, Belén, Irene Liberia Vayá y Aicha Bouchara (2016), “Acoso sexual callejero y estrategias comunicativas. Un análisis comparado entre España y Marruecos”, Comunicação Mídia e Consumo, 13 (37): 138.

Valcárcel, Amelia (2008), Feminismo en el mundo global, Madrid, Cátedra.

West, Candance y Don Zimmerman (2009), “Accounting for Doing Gender”, Gender \& Society, 23 (1): 112-122.

Witkowska, Eva y Anders Kjellberg (2005), “Dimensions of Peer Sexual Harassment in Swedish High Schools: What Factor Structures Show the Best Fit to Girls' and Boys' Self-Reports?", Sex Roles, 56: 677-687. 